\title{
Anti-cancer effect and gene modulation of ET-743 in human biliary tract carcinoma preclinical models
}

\author{
Caterina Peraldo-Neia ${ }^{{ }^{*} \dagger}$, Giuliana Cavalloni ${ }^{2 \dagger}$, Marco Soster ${ }^{3}$, Loretta Gammaitoni ${ }^{2}$, Serena Marchiò ${ }^{3}$, \\ Francesco Sassi ${ }^{4}$, Livio Trusolino ${ }^{4}$, Andrea Bertotti ${ }^{4}$, Enzo Medico ${ }^{5}$, Lorenzo Capussotti ${ }^{6}$, Massimo Aglietta ${ }^{1,2}$ \\ and Francesco Leone $e^{1,2}$
}

\begin{abstract}
Background: Standard chemotherapy in unresectable biliary tract carcinoma (BTC) patients is based on gemcitabine combined with platinum derivatives. However, primary or acquired resistance is inevitable and no second-line chemotherapy is demonstrated to be effective. Thus, there is an urgent need to identify new alternative (chemo)therapy approaches.

Methods: We evaluated the mechanism of action of ET-743 in preclinical models of BTC. Six BTC cell lines (TFK-1, EGI-1, TGBC1, WITT, KMCH, HuH28), two primary cell cultures derived from BTC patients, the EGI-1 and a new established BTC patient-derived xenografts, were used as preclinical models to investigate the anti-tumor activity of ET-743 in vitro and in vivo. Gene expression profiling was also analyzed upon ET-743 treatment in in vivo models.

Results: We found that ET-743 inhibited cell growth of BTC cell lines and primary cultures (IC50 ranging from 0.37 to $3.08 \mathrm{nM}$ ) preferentially inducing apoptosis and activation of the complex DNA damage-repair proteins (p-ATM, p-p53 and p-Histone H2A.x) in vitro. In EGI-1 and patient-derived xenografts, ET-743 induced tumor growth delay and reduction of vasculogenesis. In vivo ET-743 induced a deregulation of genes involved in cell adhesion, stress-related response, and in pathways involved in cholangiocarcinogenesis, such as the IL-6, Sonic Hedgehog and Wnt signaling pathways.
\end{abstract}

Conclusions: These results suggest that ET-743 could represent an alternative chemotherapy for BTC treatment and encourage the development of clinical trials in BTC patients resistant to standard chemotherapy.

Keywords: Biliary tract carcinoma, ET-743, Preclinical model, Chemotherapy, Patient-derived xenograft

\section{Background}

Biliary tract carcinoma (BTC) is a particularly lethal malignancy arising from the ductal epithelium of the biliary tree, either within the liver or from the extrahepatic bile ducts [1]. Most patients with BTC are diagnosed at advanced stages, and have a life expectancy of $<12$ months [2].

Chemotherapy is commonly used to improve patients' outcome and to control tumor progression. Different chemotherapeutic agents have been employed [3]; few randomized trials have established the combination of

\footnotetext{
* Correspondence: caterina.peraldoneia@ircc.it

${ }^{\dagger}$ Equal contributors

'University of Turin Medical School, Department of Oncology,

IRCCS-Candiolo, Strada provinciale 142, Km 3.95, Candiolo, 10060 Turin, Italy Full list of author information is available at the end of the article
}

gemcitabine (GEM) and platinum compounds to be the standard of therapy for unresectable BTC patients [4-6]. In these studies, overall survival (OS) in the GEM and platinum combination arm was of about 11 months. These studies, therefore, demonstrated that there are very limited possibilities for prolonging survival of BTC patients, and that it is crucial to find novel therapeutic strategies for the treatment of BTC patients.

Ecteinascidin-743 (ET-743), a compound isolated from the marine tunicate Ecteinascidia turbinata $[7,8]$ with a potent cytotoxic activity against a variety of tumors in vitro and in vivo $[9,10]$, has been approved for treatment of softtissue sarcoma and ovarian cancer [11,12]. Its mechanism of action is linked to binding to the minor groove of DNA and to a variety of modulatory effects on the tumor

\section{Ciomed Central}

(c) 2014 Peraldo-Neia et al.; licensee BioMed Central Ltd. This is an Open Access article distributed under the terms of the Creative Commons Attribution License (http://creativecommons.org/licenses/by/4.0), which permits unrestricted use, distribution, and reproduction in any medium, provided the original work is properly credited. The Creative Commons Public Domain Dedication waiver (http://creativecommons.org/publicdomain/zero/1.0/) applies to the data made available in this article, unless otherwise stated. 
microenvironment, including changes in the production of several inflammatory mediators like the chemokines CCL2 and CXCL8, the cytokine IL-6 and the angiogenic factor VEGF [13]. Chronic inflammation contributes to cancerogenesis and disease progression in different types of solid tumors [14,15]. Tumor-associated macrophages (TAMs) represent the major class of immune cells within the tumor microenvironment [16] and have been shown to promote tumor proliferation, increase invasiveness and mitigate $\mathrm{T}$ cell-mediated cytotoxic antitumor responses [17-19]. They are regarded as potential targets in anticancer therapies and, in this context, ET-743 may represent a suitable tool to overcome myelomonocytic cell-mediated exacerbation of the malignant phenotype and immune suppression [20]. In BTC the presence of TAM has been documented and correlated with a worse prognosis [21] but there are no preclinical data of ET-743 activity in BTC. Literature reports only the anecdotal case of a BTC patient involved in a phase I study who experienced a complete metabolic response with ET-743 [22].

Here, we investigated the potential anti-tumor activity of ET-743 and its effect on gene expression profiling in human preclinical models of BTC.

\section{Methods}

\section{Cell lines and patients}

The extrahepatic cholangiocarcinoma (ECC) cell lines TFK-1 and EGI-1, the intrahepatic cholangiocarcinoma (ICC) cell line $\mathrm{HuH} 28$ and the gallbladder carcinoma (GBC) cell line TGBC1 (Cell Bank, RIKEN Bioresource Center Riken Cell Bank, Japan) were cultured in RPMI 1640 containing 10\% fetal bovine serum (FBS) (all from Sigma-Aldrich, St. Louis, MO, USA), 100 U/mL penicillin and $100 \mu \mathrm{g} / \mathrm{mL}$ streptomycin (P/S) (Life Technologies Gathersburg, MD). The ECC WITT cells and the ICC mixed to hepatocarcinoma $\mathrm{KMCH}$ cells (provided by Dr. Andersen, Laboratory of Experimental Carcinogenesis, National Institutes of Health, Bethesda, Maryland), were cultured in DMEM (Sigma-Aldrich) plus 10\% FBS. The authentication of all the cell lines was performed by using Cell_ID system (Promega, Corporation, Madison, WI, USA) comparing their profiles with those published on the DMSZ database. Human endothelial cells Huvec were cultured on gelatin-coated plastic, in Medium 199 plus 20\% FBS, added of P/S, $50 \mu \mathrm{g} / \mathrm{ml}$ of heparin (Sigma-Aldrich,) and $100 \mu \mathrm{g} / \mathrm{ml}$ of bovine brain extract (Sigma-Aldrich).

Primary cell cultures were isolated from peritoneal liquid obtained by paracentesis procedure from two patients with ICC. They received the combination of gemcitabine and oxaliplatin and progressed after 5 and 2 months, respectively. Only CK7/19 positive cells were cultured in KODMEM/F12 (Life Technologies) plus $10 \%$ FBS.
Biological material for the set-up of primary cell cultures and patient derived xenograft (PDX or xenopatient) protocol were obtained from ICC patients who have signed the informed consent, following institutional review boardapproved protocols "PROFILING Protocol, n 001-IRCC-00 IIS-10" approved by Comitato Etico Interaziendale of A. O.U. San Luigi Gonzaga, Orbassano, Torino, Italy). This institutional study provides molecular genetic analysis, set up of primary cultures and the creation of PDX from tumor biological samples (primary tumor, metastasis, tumor cells taken under paracentesis or thoracentesis procedures, and blood) from patients with colorectal cancer, prostate cancer, head and neck cancer, primary tumors of the stomach, primary tumors of the liver and biliary tract, glioblastoma, ovarian or primary tumors with metastases, primary tumors of the lung, primary tumors of the breast, rare cancers defined by incidence $\leq 5 \times 10^{6}$, sarcomas and metastatic melanomas.

\section{Drugs}

ET-743 from PharmaMar (Pharma Mar, S.A., Madrid, Spain) was dissolved in PBS at $1.3 \mathrm{mM}$ for in vivo experiments, and at a concentration of $1 \mu \mathrm{M}$ in dimethyl sulfoxide (DMSO) (Sigma-Aldrich) for in vitro experiments, and stored at $-20^{\circ} \mathrm{C}$. For in vitro experiments, $0.001 \%$ DMSO was added to ET-743-untreated cells.

\section{Cell growth assay}

Cells (3000/well) were seeded onto 96-well tissue culture plates; after 24 hours they were treated with escalating doses of ET-743 (0.078-10 nM) in appropriate culture medium added of $10 \%$ FBS for another 72 hours. Cell growth was evaluated with the Cell Titer-Glo ${ }^{\circ}$ cell viability assay (Promega). All tests were performed in quadruplicate and repeated in three independent experiments. IC50 values, dose of drug that inhibits 50\% of the cell growth compared with control calculated for each cell line after 72 hours of drug treatment, was calculated using the CalcuSyn software, based on the Chou-Talalay method.

\section{DNA content and apoptosis analysis}

To determine the cell cycle status, $1 \times 10^{6}$ cells/well were seeded onto six-well tissue culture plates for 24 hours, and then treated with $5 \mathrm{nM}$ ET-743 for an additional 48 hours. Cells were then fixed in $70 \%$ ethanol at $-20^{\circ} \mathrm{C}$ for 16 hours followed by washing in PBS, resuspended in staining solution $(50 \mu \mathrm{g} / \mathrm{ml}$ Propidium Iodide, PI $+100 \mu \mathrm{g} / \mathrm{ml}$ RNaseA in PBS) (Sigma-Aldrich) and overnight incubated at $4^{\circ} \mathrm{C}$. For apoptosis analysis, $1 \times 10^{5}$ cells were washed in Binding Buffer (0.01 M Hepes, 0.15 M NaCl, $5 \mathrm{mM} \mathrm{CaCl}_{2}$ ), stained with allophycocyanin (APC) conjugated AnnexinV/PI (Bender MedSystems Wein, Austria) and incubated for 15 minutes at room temperature. DNA content and 
apoptosis level were determined by flow cytometry using Cyan and Summit Research Software (Dako, Glostrup, Denmark). Three independent experiments were performed.

\section{Western blot}

Cells were lysed in boiling buffer (10\% SDS, $0.5 \mathrm{M}$ Tris $-\mathrm{HCl} \mathrm{pH}$ 6.8) and centrifuged at $20,000 \times g$ for 30 minutes; $20 \mu \mathrm{g}$ of protein were separated on $7.5-15 \%$ SDS-PAGE and transferred onto $0.45-\mu \mathrm{m}$ nitrocellulose membranes (GE Healthcare Europe, Milan, Italy). Blots were stained using standard procedures and signals were revealed by a chemiluminescence reagent (Euroclone, Milan, Italy). Horseradish peroxidase (HRP)-linked secondary antibodies, anti-phospho-Ataxia Telengectasia (Ser 1981) (ATM), anti-ATM, anti-phospho-p53, anti-p53 and anti-vinculin were from Cell Signaling Technology (Beverly, USA); anti-phospho-Histone H2A.x (Ser 139) was from Millipore (Temecula, CA) and anti-Histone H2A.x was from GeneTex (San Antonio, Texas). Three independent experiments were performed.

\section{Antitumor activity of ET-743 in in vivo models of BTC}

We investigated the antitumor activity of ET-743 in preclinical in vivo models of BTC. For in vivo studies, NOD (Non-Obese Diabetic)/Shi-SCID (severe combined immunodeficient) female mice (4-6 weeks old) (Charles River Laboratory) were maintained under sterile conditions in micro-isolator cages at the animal facilities of the IRCCS-Candiolo. All animal procedures were approved by the Institutional Ethical Committee for Animal Experimentation (Fondazione Piemontese per la Ricerca sul Cancro) and by the Italian Ministry of Health.

In three independent experiments, 14 mice, either in EGI-1-xenograft $\left(5 \times 10^{6}\right.$ cells/mouse subcutaneously injected), or an ICC patient derived xenograft model [23], here named CHC001PDX, were randomized to receive intra venous (i.v.) weekly $0.15 \mathrm{mg} / \mathrm{Kg}$ ET-743 [24-26] or drug vehicle (PBS) for 3 weeks (7 mice for arm of treatment). Tumor size was measured weekly. Volumes were calculated using the formula $\mathrm{V}=\mathrm{AxB}^{2} / 2(\mathrm{~V}=$ tumor volume, $\mathrm{A}=$ largest diameter; $\mathrm{B}=$ smallest diameter). Mean volumes of treated and untreated xenografts were compared by two-way Anova, considering a p-value $<0.05$ (C.I. $95 \%$ ) as statistically significant. Tumors were formalinfixed, paraffin-embedded (FFPE) for immunohistochemical evaluations.

\section{Immunohistochemistry on BTC in vivo models}

For the evaluation of ET-743 effects on tumor xenografts, tissue sections were stained with anti-Ki67/MIB1 (Dako) and anti-CD31 (BD) antibodies, followed by incubation with secondary antibody (Invitrogen). Ki67 expression was evaluated in 10 fields for each section at 40x by Image); CD31 quantification was performed on $10 \mathrm{z}$-stack images for each slide at $20 \times$ magnification by calculating the positively stained vessel area. Expression values of treated and untreated xenografts were compared by two tailed unpaired $T$-test, assuming a $\mathrm{p}$-value $<0.05$ (C.I. 95\%) as statistically significant.

\section{Microarray analysis}

For gene expression profiling (GEP), total RNA was extracted by using TissueLyser LT (Qiagen) and then purified by Absolutely RNA miRNA kit (Agilent Technologies), following manufacturers' protocols. Quantitative and qualitative evaluation of total RNA was performed by Nanodrop and BioAnalyzer respectively. For GEP analysis, 100 ng of total RNA was amplified and labeled using Low Input Quick Amp Labeling Kit, one-color kit (Agilent Technologies). Six hundred ng of labeled RNA were hybridized on SurePrint G3 Human Gene Expression $8 \times 60 \mathrm{~K}$ v2 glass arrays. The experiment was carried out by two technical replicates. Arrays were scanned and images analyzed by the Feature Extraction Software from Agilent Technologies (version 10.7), and raw data were then processed using the Bioconductor package Limma (Linear models for microarray analysis). Background correction was performed with the normexp method with an offset of 50, and quantile was used for the between-array normalization. The empirical Bayes method was used to compute a moderated t-statistics [27]. The threshold for $|\log \mathrm{FC}|$ of 0.58 and a $P$ value $<0.05$ was used to identify modulated transcripts. Microarray data were deposited in Gene Expression Omnibus (GSE63043).

\section{Results}

ET-743 induces cell cycle perturbation, apoptosis, and activation of proteins involved in DNA damage-repair in biliary tract carcinoma cells in vitro

To investigate the capability of ET-743 to interfere with cell growth, BTC cell lines and primary cultures were treated with escalating doses $(0.078-10 \mathrm{nM})$ of ET-743 for 72 hours. As indicated in Figure 1A, all the BTC cells proved to be sensitive to ET-743 treatment, with an IC50 ranging from $0.37 \mathrm{nM}$ for ICP-2 cells to $3.08 \mathrm{nM}$ for ICP-3 cells. Interestingly, the most responsive BTC cells, $\mathrm{HuH} 28$ and ICP-2, resulted resistant to gemcitabine (Additional file 1: Table S1) [28]. Cell cycle status changes and induction of apoptosis by ET-743 were also examined on BTC cells after 48 hours of treatment. As shown in Figure 1B and in Additional file 2: Figure S1, ET-743 caused a different distribution in cell cycle phases. The common evidence was an increment in the subG $\mathrm{G}_{0}$ phase cell fraction, particularly evident in the $\mathrm{KMCH}$ cells, indicating that the growth inhibition by ET-743 could be mainly due to the induction of apoptotic cell death. A more specific assay, in fact, indicated that, after 48 hours of treatment, ET-743 induced apoptosis in the tested cell lines, 


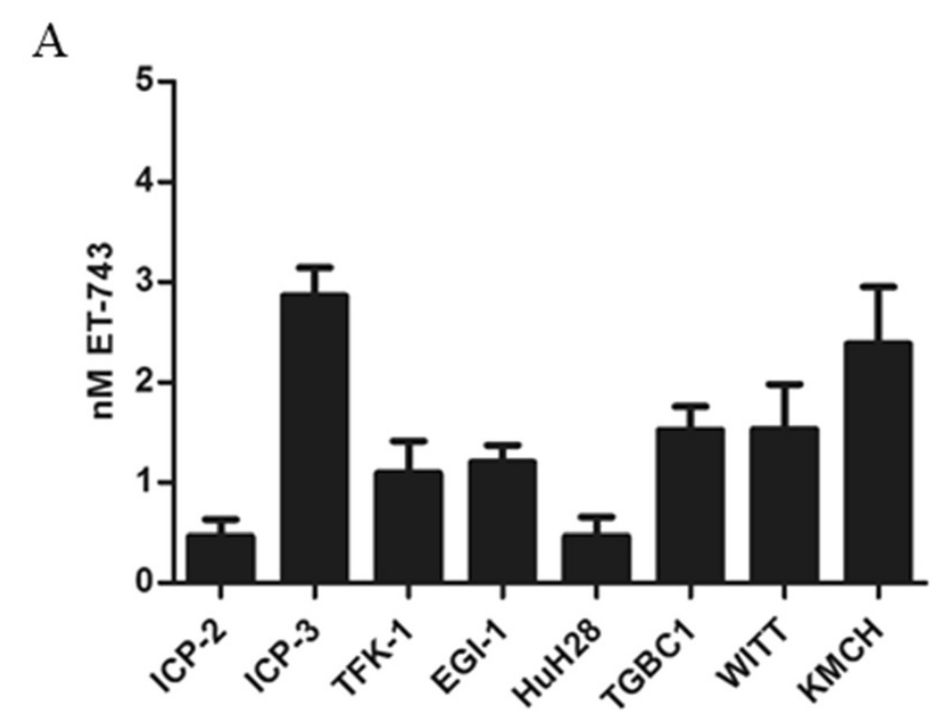

B
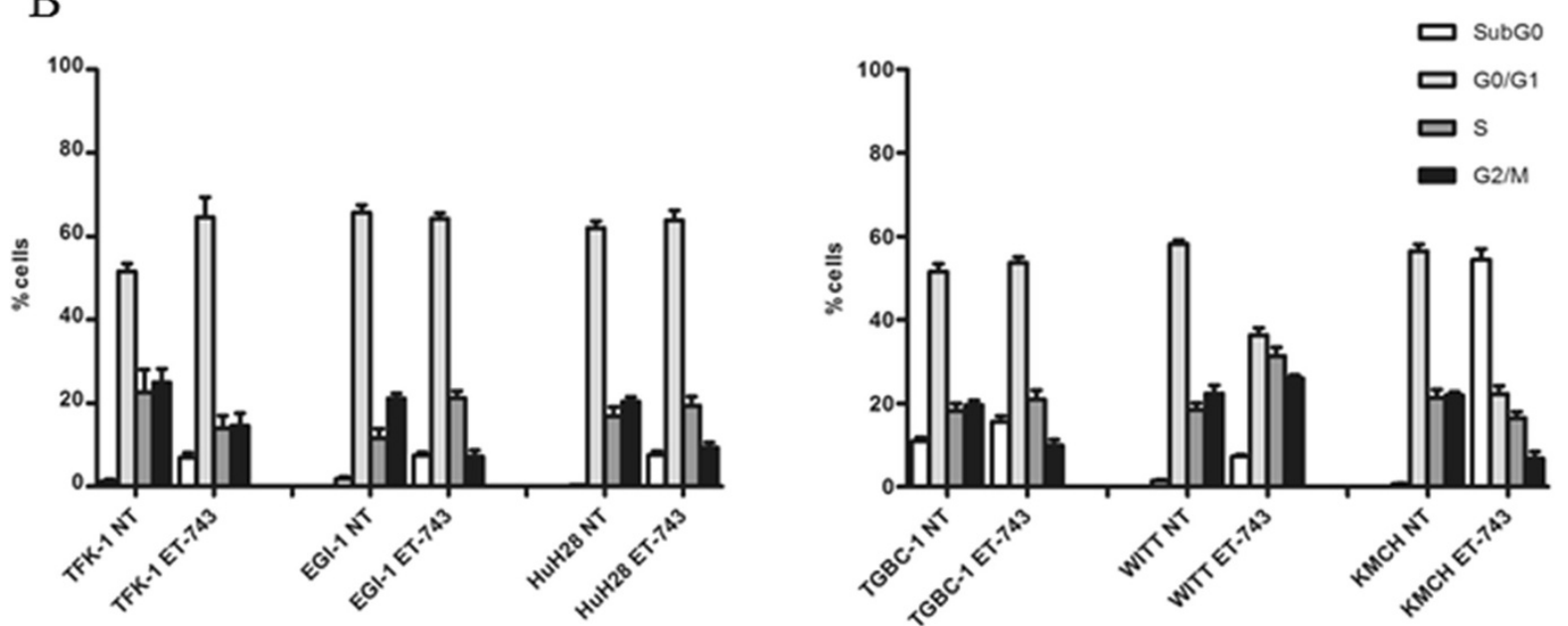

C

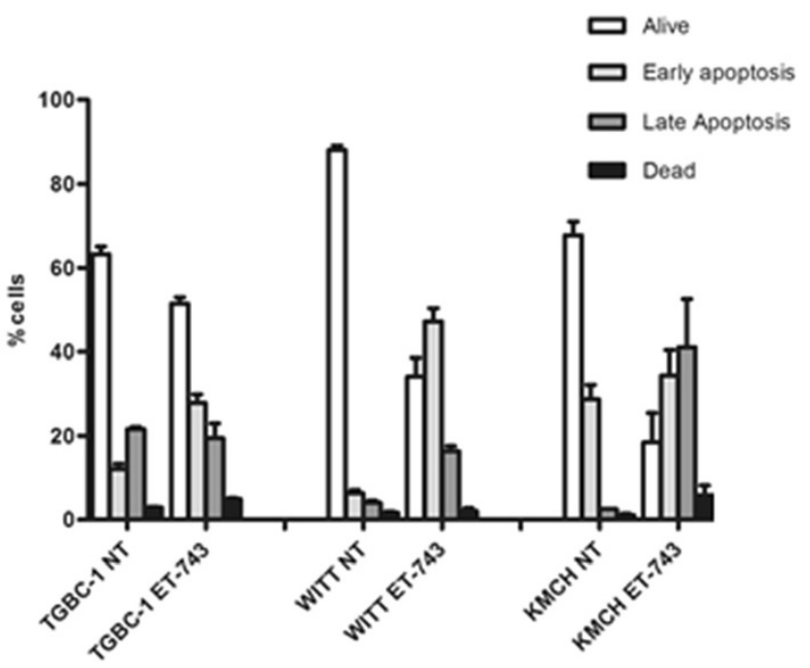

Figure 1 (See legend on next page.) 
(See figure on previous page.)

Figure 1 Effect of ET-743 on proliferation, cell cycle and apoptosis in vitro. (A) ET-743 inhibits growth in vitro. Cells were treated with escalating doses of ET-743 (0.078-10 nM) for 72 hours and cell growth was evaluated by Cell Titer-Glo ${ }^{\oplus}$ cell viability assay. IC50 values were calculated using the CalcuSyn software, based on the Chou-Talalay method. ICP-2/3: primary cells derived from two intrahepatic cholangiocarcinoma (ICC) patients. TFK-1, WITT and EGI-1: extrahepatic cholangiocarcinoma cell lines; HuH28 ICC cell line; TGBC1: gallbladder carcinoma cell line; KMCH: ICC mixed with hepatocarcinoma cell line. The histograms represent the mean of IC50 values (bars represent SEM) from three independent experiments. Effect of ET-743 on cell cycle (B) and on apoptosis (C) in vitro. BTC cell lines were treated with $5 \mathrm{nM}$ of ET-743 for $48 \mathrm{~h}$ and subjected to cell cycle analysis and apoptosis detection by AnnexinV/PI staining by flow cytometry as described in methods. The bars represent the average with SEM of percentage of cells in each phase (B) and apoptotic cells (C) of three independent experiments. NT: no treated cells.

as shown in Figure $1 \mathrm{C}$ and in Additional file 3: Figure S2. We investigated whether ET-743 was capable of activating the complex DNA damage-repair protein machine. For this purpose, BTC cells were treated for 24 hours with $5 \mathrm{nM}$ ET-743 and analyzed for the expression level of p-ATM, p-p53, and p-Histone H2A.x. We observed that phosphorylation of ATM, Histone H2A.x, and p53 was increased upon ET-743 treatment (Additional file 4: Figure S3).

\section{ET-743 reduces tumor growth and angiogenesis in in vivo models of BTC}

The antitumor activity of ET-743 was investigated in BTC preclinical in vivo models, both on EGI-1 xenograft and in
CHC001PDX. Each cohort of xenografts was randomized to receive ET-743 $(0.15 \mathrm{mg} / \mathrm{Kg})$ or drug vehicle (PBS) i.v. weekly for 3 weeks following the schedule of treatment of D'Incalci and coll. in other human xenograft models (23). Tumor size was measured weekly until the sacrifice of the animals. One week after the third administration (day 21 ), a significant delay in tumor growth was observed in CHC001PDX mice treated with ET-743 $(\mathrm{p}=0.04$, Figure 2A). Similar results were obtained in EGI-1 xenografts $(\mathrm{p}=0.001)$ (Figure $2 \mathrm{~B})$. Tumors harvested from CHC001PDX and EGI-1 xenografts treated with either PBS or ET-743 were subjected to immunohistochemical analysis for Ki67/MIB1 proliferation index detection. A reduction in

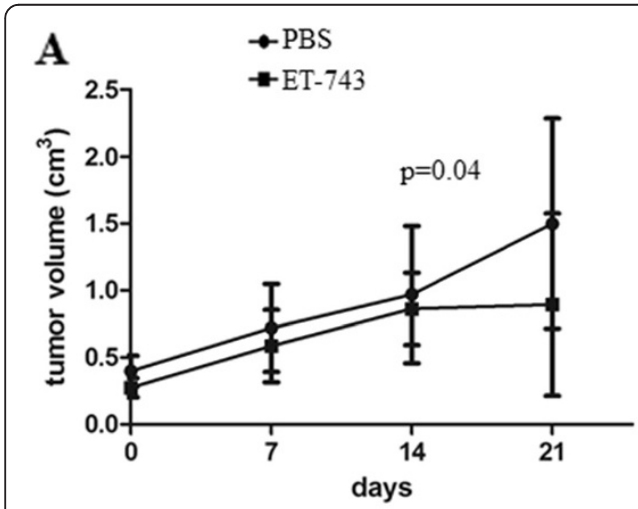

B

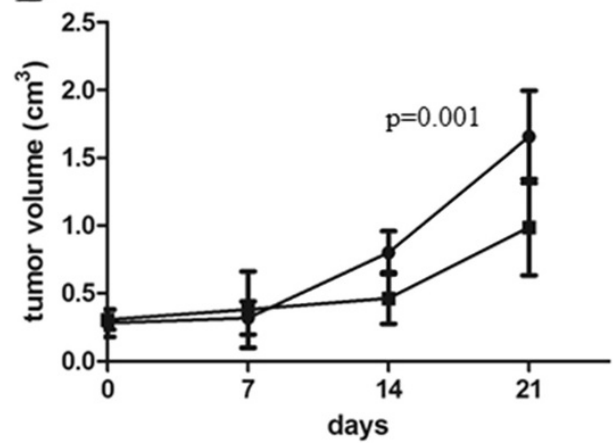

C

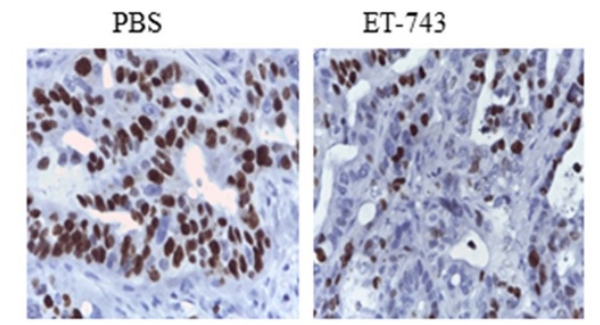

D
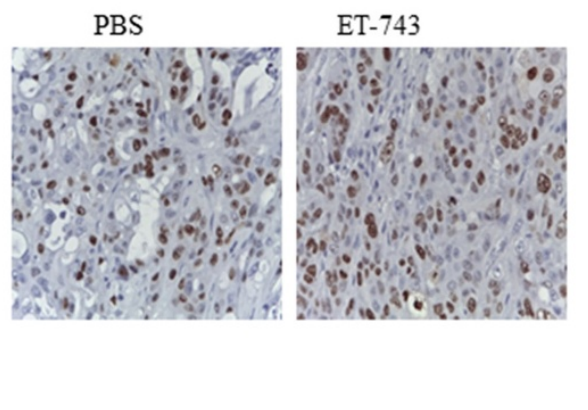

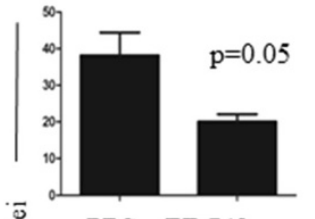

PBS ET-743

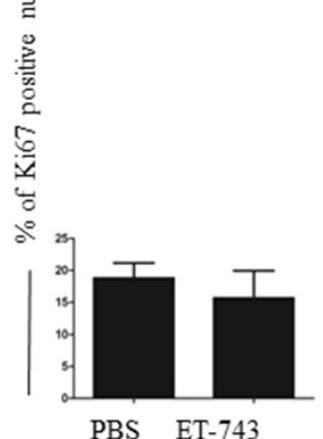

Figure 2 In vivo antitumor activity of ET-743 in human BTC preclinical models. The graphs indicate the mean tumor volume ( $\mathrm{cm}^{3}$ ) weekly measured: 0 (start of treatment), 7, 14, and 21 days after treatment with ET-743 (weekly $0.15 \mathrm{mg} / \mathrm{Kg}$ ET-743 or PBS in mice control cohort) (error bars: SEM). Seven mice for each arm of treatment in three independent experiments were used. One week after the last drug administration, a significant slow of tumor growth was shown in treated mice in both CHC001PDX (A) and EGl-1-xenografts (B). Ki67 staining of section derived from CHC001PDX (C) and EGI-1 xenograft (D) tumors treated with PBS or ET-743 and relative quantification. A statistical significant reduction of Ki67 positive cells was revealed in the ET-743-treated CHC001PDX group. 
the number of proliferating cells in treated compared to untreated CHC001PDX mice was revealed (Figure 2C; Ki67: $\mathrm{p}=0.05)$. In EGI-1 xenografts, we found a moderate inhibition of proliferation in treated compared to untreated mice (Figure 2D). By contrast, we found a weakly but not significant increase of apoptotic cells in vivo (data not shown).

We observed that ET-743 treated-tumors were macroscopically less vascularized compared with the control cohorts of mice. Thus, we verified the status of tumor vasculature at the microscopic level. Tumor sections from control and ET-743 treated CHC001PDX/EGI-1 xenografts were stained for the endothelial marker CD31. A significant reduction in the number of tumor blood vessels was observed in ET-743-treated mice (Figure 3) $(\mathrm{p}<0.0001$ and $\mathrm{p}=0.003$ for EGI-1-xenograft and CHC001PDX respectively). Further, we evaluated the in vitro effect of drug on human endothelial Huvec cells after 72 hours of treatment with ET-743. A potent inhibitory effect on proliferation was revealed, with an IC50 of $0.16 \mathrm{nM}$, comparable to those found in the most sensitive BTC cells (data not shown).

\section{ET-743 modulates genes involved in cell adhesion processes, in stress response, and pathways involved in cholangiocarcinogenesis}

The impact of ET-743 on gene expression was assessed in in vivo models. Upon ET-743 treatment, 1346 differentially expressed probes were identified in CHC001PDX, 628 down-regulated and 718 up-regulated. In EGI-1 xenograft, 1195 differentially expressed probes were identified, 584 down-regulated and 611 up-regulated. Gene Ontology

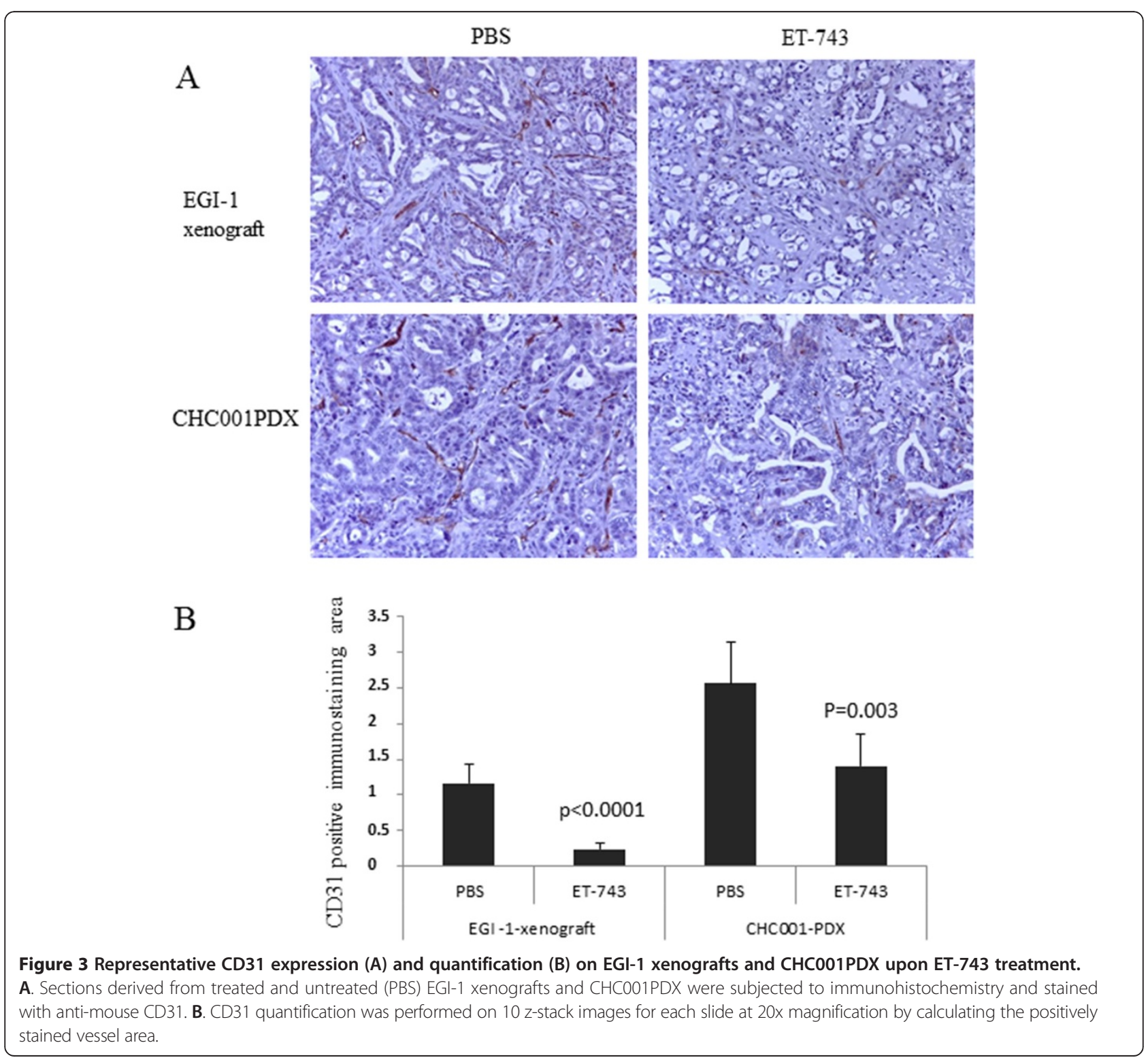


analysis was performed on the two datasets (significant p-value <0.01), considering up and down-regulated genes separately. We identified at least 20 deregulated biological processes upon ET-743 treatment in CHC001PDX and EGI-1 xenografts (Additional file 5: Table S2). Comparing the two models, we found an overlap of differentially expressed probes upon ET-743 treatment, whose expression is able to subdivide treated from untreated samples by an unsupervised hierarchical clustering analysis (Figure 4). In particular there are 46 common down-regulated genes, 12 out of them (i.e., CADM1, WISP1, CDH2, COL14A1, THY1, CDH11, PSTPIP1, PCDHGA8, THBS2, CLDN2, NCAM1, AEBP1) are involved in cell adhesion processes; further, $\mathrm{CDH} 2$ / $\mathrm{N}$-Cadherin, a member of the trefoil factor (TFF) gene family, the TFF3 gene, transforming growth factor- $\beta 1$ (TGF- $\beta 1$ ) and N-CAM1, have been previously associated to BTC [29-34]. We also found 16 common up-regulated genes, 5 out of them (HSPA6, OBFC2A, DNAJB4, IL6R, AOX1) are involved in response to stress (Additional file 6: Table S3). Results obtained by microarray experiments were validated by quantitative RT-PCR for some selected deregulated genes (CDH11, TFF3, C FAM5C, IL6R, KCMNA1) (data not shown). Further, pathway analysis of both datasets was performed using PathwayMiner software (www.biorag.org); using three different databases, we found 12 common pathways significantly deregulated by ET-743 (Additional file 7: Table S4): among them the IL-6, the Sonic Hedgehog and the Wnt signaling pathways are involved in cholangiocarcinogenesis [35-38].

\section{Discussion}

ET-743 has been approved for treatment of ovarian cancer and soft-tissue sarcoma with significant activity
A

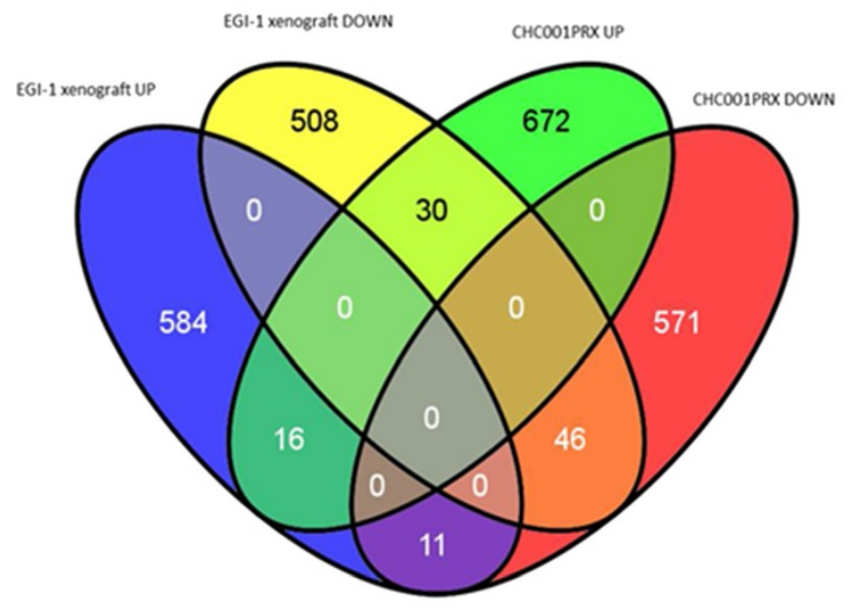

B

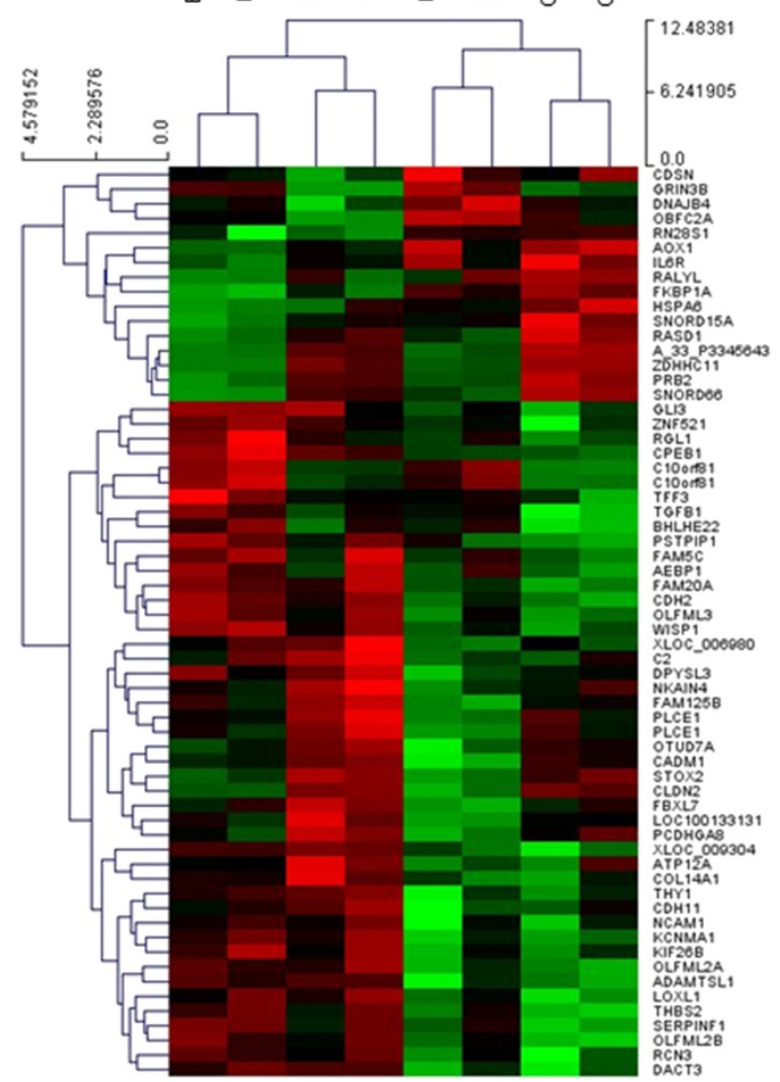

Figure 4 Gene expression analysis of the in vivo models after treatment with ET-743. A. Venn Diagramm showed the differentially expressed probes distribution in the two in vivo models. B. Hierarchical clustering applied to the expression matrix of genes modulated in a concordant manner by the treatment in both CHC001PDX/EGI-1 models, using Euclidean distance as similarity metrics and average linkage as linkage method. Genes were median center and divided by standard deviation. NT: not treated mice; TREATED: treated with ET-743. 
in liposarcomas and leiomyosarcomas, both as a single agent and in combination with other drugs. Here, we demonstrated that ET-743 has an antitumor activity both in vitro and in vivo in preclinical models of human BTC. We reported that ET-743 inhibits BTC in vitro cell growth. Interestingly, the most responsive models to ET-743 were represented by the $\mathrm{HuH} 28$ cell line, previously demonstrated to be resistant to GEM in vitro [28] and the ICP-2 primary tumor cell cultures derived from GEMOX-resistant patient. Cell cycle studies on ET-743treated BTC cells, demonstrated that the chemotherapy acts by modifying the cell cycle status, mostly inducing an increase of sub- $G_{0}$ phase cell fraction and triggering apoptosis as preferential mechanism. It has been demonstrated that ET-743 causes double-strand DNA damage, detectable by Ser139 phosphorylation of the histone H2A. $\mathrm{x}$. This event triggers a cascade leading to the activation of ATM, and consequently of p53 $[39,40]$. Although BTC cell lines display different p53 mutational status, and in particular TFK-1 cells are p53-deleted, we did not find any significant correlation between response to ET-743 and p53 mutational status in these cell lines. This is in agreement with a previous report [7].

In recent years, clinical validation of anticancer therapies has benefited from in vivo models derived from the direct implantation of human tumors in immunocompromized mice. These preclinical models present the advantage to recapitulate the biological characteristics of the primary tumor and represent a useful tool for the study the biology of tumors and the clinical response to new therapeutic approaches $[13,41,42]$. To investigate the in vivo antitumor activity of ET-743, we created BTC mouse xenograft models. By using one of such PDX models and a conventional xenograft from a BTC cell line (EGI-1), we showed that three administrations of ET-743 are sufficient to cause a significant delay of tumor growth compared to the respective untreated control groups. Tumor growth delay by ET-743 could be ascribed to a decrease in the number of tumor proliferating cells, and a net decrease of tumor vessel formation. We were not be able to demonstrate induction of apoptosis in vivo suggesting that in vitro the activity could be more directed to BTC cells, but in vivo ET-743 is also directed against the tumor microenvironment, in particular by decreasing the tumor-associated macrophages and down-regulation of cytokines, chemokines and angiogenic factors [16].

The transcriptional signature upon ET-743 treatment revealed a panel of common deregulated genes. Among them, 12 cell adhesion related genes were down-regulated, while 5 stress response genes were up-regulated. Interestingly, ET-743 reduced the expression of WISP1, which has been associated to a more aggressive phenotype of BTC [43]; another down-regulated gene, TFF3, a member of the trefoil factor $(T F F)$ gene family, was demonstrated to be associated with tumor progression in colorectal cancer [30] and in BTC [44]. ET-743 also induced the downmodulation of TGF- $\beta 1$, highly expressed in BTC and contributing to the angiogenic switch in preclinical models [32]. Moreover, Shimizu and coll. [31] provided evidence that TGF- $\beta 1$ supports BTC cell growth, indicating its potential role as a molecular target. Further, we found a deregulation of genes involved in the IL-6, the Sonic Hedgehog and the Wnt signaling pathways, all demonstrated to be involved in cholangiocarcinogenesis [35-38].

As ET-743 inhibited the neoplastic compartment but also affected the tumor micro-environment, it is likely to be more effective for those malignancies as BTC in which chronic inflammation is known to contribute in tumor progression by causing myelomonocitic infiltration and producing chemokines and cytokines. However, these aspects are more difficult to be reproduced in preclinical models and need to be explored in a clinical setting.

\section{Conclusions}

In conclusion, our data suggest that ET-743 could be a promising alternative chemotherapy for BTC treatment, providing a strong rationale in the design of a clinical trial to evaluate the activity of ET-743 in BTC patients resistant to GEM-based therapeutic regimens.

\section{Additional files}

Additional file 1: Table S1. Comparison of IC50 values after treatment with GEM or ET-743 on BTC cells.

Additional file 2: Figure S1. Representative histograms of distributions of TFK-1, WITT, and KMCH on cell cycle phases. NT: not treated cells.

Additional file 3: Figure S2 Representative Dot plots analysis of apoptosis induction in TGBC1, TFK-1, WITT, and KMCH cell lines.NT, not treated; ET-743, treated with drug.

Additional file 4: Figure S3. ET-743 induces the phosphorylation of proteins involved in DNA damage-repair in BTC cell lines. Cells were treated with $5 \mathrm{nM}$ of ET-743 for 24 hours followed by Western blot analysis to investigate the phosphorylation status of ATM, p53, and H2A.x.

Additional file 5: Table S2. Gene Ontology of ET-743 treated vs untreated in vivo models. A. CHC001PDX treated vs CHC001PDX untreated: BPall pv $<0.01$ - BG Agilent HumanGenome. B. EGl-1 xenograft-treated vs EGI1 xenograft-untreated: BPall pv $<0.01$ - BG Agilent HumanGenome.

Additional file 6: Table S3. Common deregulated (46 down-regulated and 12 up-regulated) elements between CHC001PDX and EGl-1 xenograft.

Additional file 7: Table S4. Common deregulated pathways obtained by PathwayMiner software, using three different databases. A p value $<0.05$ was considered as statistically significant.

\section{Abbreviations}

ET-743: Ecteinascidia turbinate-743; BTC: Biliary tract carcinoma; IL-6: Interleukin-6; GEM: Gemcitabine; OS: Overall survival; VEGF: Vascular endothelial growth factor; TAMs: Tumor-associated macrophages; ECC: Extrahepatic cholangiocarcinoma; ICC: Intrahepatic cholangiocarcinoma; GBC: Gallbladder carcinoma; FBS: Fetal bovine serum; DMSO: Dimethyl sulfoxide; PDX: Patient derived xenograft; PR: Primitive; NOD/Shi-SCID: Non-Obese Diabetic/severe combined immunodeficient; PBS: Phosphate buffered saline; PI: Propidium lodide; APC: Allophycocyanin; HRP: Horseradish peroxidase; GEP: Gene expression profiling; SEM: Standard error of the mean. 


\section{Competing interests}

The authors declare that they have no competing interests.

\section{Authors' contributions}

CPN and GC (co first-authors) designed the study, conceived and carried out the experiments, analyzed data and wrote the article; MS carried out experiments and performed statistical analysis; LG carried out experiments and revised the article; SM performed statistical analysis and revised the article; FS carried out experiments and performed statistical analysis; LT and $A B$ revised the article; EM interpreted microarray data; $F L$ and $M A$ designed the study, wrote and revised the article. All authors approved the final version of the manuscript.

\section{Acknowledgements}

We would like to thank Radhika Srinivasan, PhD, for extensive revision of the manuscript. CPN: Fellowship sponsored by Associazione Italiana per la Ricerca sul Cancro (AIRC) (University of Turin); GC: FPO; MS: Fellowship sponsored by AIRC; LG: FPO. SM: My First AIRC Grant (AIRC-MFAG), Regione Piemonte Ricerca Sanitaria Finalizzata Under 40, Banca d'Alba, Fondazione Piemontese per la Ricerca sul Cancro (FPRC) Intramural Grant 5×1000 2008; FS: fellowship sponsored by Fondazione Umberto Veronesi (FUV)-Young Investigator Programme 2013; LT: AIRC, 2010 Special Program Molecular Clinical Oncology $5 \times 1000$, project 9970, AIRC Investigator Grants, projects 10116 and 14205; AB: AACR, American Association for Cancer Research - Fight Colorectal Cancer Career Development Award, MIUR FIRB, Ministero dell'Università e della Ricerca, Fondo per gli Investimenti della Ricerca di Base - Futuro in Ricerca. MA: University of Turin. FL: University of Turin.

\section{Financial support}

This work was supported by grants from "Progetti di Ricerca Rete Oncologica Piemonte-Valle d'Aosta" and "Fondazione Piemontese per la Ricerca sul Cancro - Onlus-". Project n¹6:30 "Identificazione di nuove vie di trasduzione del segnale intracellulare sensibili ai farmaci nel colangiocarcinoma intraepatico (ICC)" 5 per Mille 2010 Ministero della Salute. CPN: Fellowship sponsored by Associazione Italiana per la Ricerca sul Cancro (AIRC) (University of Turin); GC: FPO; MS: Fellowship sponsored by AIRC; LG: FPO. SM: My First AIRC Grant (AIRC-MFAG), Regione Piemonte Ricerca Sanitaria Finalizzata Under 40, Banca d'Alba, Fondazione Piemontese per la Ricerca sul Cancro (FPRC) Intramural Grant $5 \times 1000$ 2008; FS: fellowship sponsored by Fondazione Umberto Veronesi (FUV)-Young Investigator Programme 2013; LT: AIRC, 2010 Special Program Molecular Clinical Oncology $5 \times 1000$, project 9970, AIRC Investigator Grants, projects 10116 and 14205; AB: AACR, American Association for Cancer Research - Fight Colorectal Cancer Career Development Award, MIUR FIRB, Ministero dell'Università e della Ricerca, Fondo per gli Investimenti della Ricerca di Base - Futuro in Ricerca. MA: University of Turin. FL: University of Turin.

\begin{abstract}
Author details
${ }^{1}$ University of Turin Medical School, Department of Oncology, IRCCS-Candiolo, Strada provinciale 142, Km 3.95, Candiolo, 10060 Turin, Italy. ${ }^{2}$ Fondazione del Piemonte per l'Oncologia (FPO), IRCCS-Candiolo, Strada provinciale 142, Km 3.95, Candiolo, 10060 Turin, Italy. ${ }^{3}$ Laboratory of Tumor Microenvironment, IRCCS-Candiolo, Strada provinciale 142, Km 3.95, Candiolo, 10060 Turin, Italy. ${ }^{4}$ University of Turin Medical School, Unit of Molecular Pharmacology, IRCCS-Candiolo, Strada provinciale 142, Km 3.95, Candiolo, 10060 Turin, Italy. ${ }^{5}$ Laboratory of Oncogenomics, IRCCS-Candiolo, Italy, Strada provinciale 142, Km 3.95, Candiolo, 10060 Turin, Italy. ${ }^{6}$ Department of General Surgery and Surgical Oncology, Ospedale Mauriziano Umberto I, Strada provinciale 142, Km 3.95, Candiolo, 10060 Turin, Italy.
\end{abstract}

Received: 10 July 2014 Accepted: 21 November 2014 Published: 5 December 2014

\section{References}

1. Patel T: Cholangiocarcinoma. Nat Clin Pract 2006, 3(1):33-42.

2. Anderson CD, Pinson CW, Berlin J, Chari RS: Diagnosis and treatment of cholangiocarcinoma. Oncologist 2004, 9(1):43-57.

3. Marino D, Leone F, Cavalloni G, Cagnazzo C, Aglietta M: Biliary tract carcinomas: from chemotherapy to targeted therapy. Crit Rev Oncol/Hematol 2013, 85(2):136-148.

4. Valle J, Wasan H, Palmer DH, Cunningham D, Anthoney A, Maraveyas A, Madhusudan S, Iveson T, Hughes S, Pereira SP, Roughton M, Bridgewater J:
Cisplatin plus gemcitabine versus gemcitabine for biliary tract cancer. N Engl J Med 2010, 362(14):1273-1281.

5. Valle JW, Furuse J, Jitlal M, Beare S, Mizuno N, Wasan H, Bridgewater J, Okusaka T: Cisplatin and gemcitabine for advanced biliary tract cancer: a meta-analysis of two randomised trials. Ann Oncol 2014, 25(2):391-398.

6. Okusaka T, Nakachi K, Fukutomi A, Mizuno N, Ohkawa S, Funakoshi A, Nagino M, Kondo S, Nagaoka S, Funai J, Koshiji M, Nambu Y, Furuse J, Miyazaki M, Nimura Y: Gemcitabine alone or in combination with cisplatin in patients with biliary tract cancer: a comparative multicentre study in Japan. Br J Cancer 2010, 103(4):469-474.

7. Erba E, Bergamaschi D, Bassano L, Damia G, Ronzoni S, Faircloth GT, D'Incalci M: Ecteinascidin-743 (ET-743), a natural marine compound, with a unique mechanism of action. Eur J Cancer 2001, 37(1):97-105.

8. Pommier Y, Kohlhagen G, Bailly C, Waring M, Mazumder A, Kohn KW: DNA sequence- and structure-selective alkylation of guanine N2 in the DNA minor groove by ecteinascidin 743, a potent antitumor compound from the Caribbean tunicate Ecteinascidia turbinata. Biochemistry 1996, 35(41):13303-13309.

9. Valoti G, Nicoletti MI, Pellegrino A, Jimeno J, Hendriks H, D'Incalci M, Faircloth G, Giavazzi R: Ecteinascidin-743, a new marine natural product with potent antitumor activity on human ovarian carcinoma xenografts. Clin Cancer Res 1998, 4(8):1977-1983.

10. Hendriks HR, Fiebig HH, Giavazzi R, Langdon SP, Jimeno JM, Faircloth GT: High antitumour activity of ET743 against human tumour xenografts from melanoma, non-small-cell lung and ovarian cancer. Ann Oncol 1999, 10(10):1233-1240.

11. Krasner CN, Poveda A, Herzog TJ, Vermorken JB, Kaye SB, Nieto A, Claret PL, Park YC, Parekh T, Monk BJ: Patient-reported outcomes in relapsed ovarian cancer: results from a randomized phase III study of Trabectedin with Pegylated Liposomal Doxorubicin (PLD) versus PLD Alone. Gynecol Oncol 2012, 127(1):161-167.

12. Baruchel S, Pappo A, Krailo M, Baker KS, Wu B, Villaluna D, Lee-Scott M, Adamson PC, Blaney SM: A phase 2 trial of trabectedin in children with recurrent rhabdomyosarcoma, Ewing sarcoma and non-rhabdomyosarcoma soft tissue sarcomas: a report from the Children's Oncology Group. Eur J Canc 2002, 48(4):579-585.

13. Germano G, Frapolli R, Simone M, Tavecchio M, Erba E, Pesce S, Pasqualini F, Grosso F, Sanfilippo R, Casali PG, Gronchi A, Virdis E, Tarantino E, Pilotti S, Greco A, Nebuloni M, Galmarini CM, Tercero JC, Mantovani A, D'Incalci M, Allavena P: Antitumor and anti-inflammatory effects of trabectedin on human myxoid liposarcoma cells. Cancer Res 2010, 70(6):2235-2244.

14. Schottenfeld D, Beebe-Dimmer J: Chronic inflammation: a common and important factor in the pathogenesis of neoplasia. CA Cancer J Clin 2006, 56(2):69-83

15. Kulbe H, Chakravarty P, Leinster DA, Charles KA, Kwong J, Thompson RG, Coward Jl, Schioppa T, Robinson SC, Gallagher WM, Galletta L, Australian Ovarian Cancer Study Group, Salako MA, Smyth JF, Hagemann T, Brennan DJ, Bowtell DD, Balkwill FR: A dynamic inflammatory cytokine network in the human ovarian cancer microenvironment. Cancer Res 2012, 72(1):66-75.

16. Mantovani A, Allavena P, Sica A: Tumour-associated macrophages as a prototypic type II polarised phagocyte population: role in tumour progression. Eur J Cancer 2004, 40(11):1660-1667.

17. Lewis CE, Pollard JW: Distinct role of macrophages in different tumor microenvironments. Cancer Res 2006, 66(2):605-612.

18. Allavena P, Mantovani A: Immunology in the clinic review series; focus on cancer: tumour-associated macrophages: undisputed stars of the inflammatory tumour microenvironment. Clin Exp Immunol 2012, 167(2):195-205.

19. Orre M, Rogers PA: Macrophages and microvessel density in tumors of the ovary. Gynecol Oncol 1999, 73(1):47-50.

20. Germano G, Frapolli R, Belgiovine C, Anselmo A, Pesce S, Liguori M, Erba E, Uboldi S, Zucchetti M, Pasqualini F, Nebuloni M, van Rooijen N, Mortarini R, Beltrame L, Marchini S, Fuso Nerini I, Sanfilippo R, Casali PG, Pilotti S, Galmarini CM, Anichini A, Mantovani A, D'Incalci M, Allavena P: Role of macrophage targeting in the antitumor activity of trabectedin. Cancer Cell 2013, 23(2):249-262.

21. Subimerb C, Pinlaor S, Lulitanond V, Khuntikeo N, Okada S, McGrath MS, Wongkham S: Circulating CD14(+) CD16(+) monocyte levels predict tissue invasive character of cholangiocarcinoma. Clin Exp Immunol 2010, 161(3):471-479.

22. Gore L, Rivera E, Basche M, Moulder-Thompson SL, Li J, Eppers S, Grolnic S, O'Bryant C, Cleere D, Elsayed YA, Eckhardt SG: Phase I combination study 
of trabectedin and capecitabine in patients with advanced malignancies. Invest New Drugs 2012, 30(5):1942-1949.

23. Peraldo Neia C, Cavalloni G, Chiorino G, Ostano P, Aglietta M, Leone F: Antitumor activity, gene and miRNA modulation upon ET-743 treatment in an intrahepatic cholangiocarcinoma patient derived xenograft model. In Annual Meeting of American Association for Cancer Research. San Diego, CA: Philadelphia, PA Abstract Number 5551; 2014.

24. Takahashi N, Li W, Banerjee D, Guan Y, Wada-Takahashi Y, Brennan MF, Chou TC, Scotto KW, Bertino JR: Sequence-dependent synergistic cytotoxicity of ecteinascidin-743 and paclitaxel in human breast cancer cell lines in vitro and in vivo. Cancer Res 2002, 62(23):6909-6915.

25. D'Incalci M, Colombo T, Ubezio P, Nicoletti I, Giavazzi R, Erba E, Ferrarese L, Meco D, Riccardi R, Sessa C, Cavallini E, Jimeno J, Faircloth GT: The combination of yondelis and cisplatin is synergistic against human tumor xenografts. Eur J Cancer 2003, 39(13):1920-1926.

26. Romano M, Frapolli R, Zangarini M, Bello E, Porcu L, Galmarini CM, García-Fernández LF, Cuevas C, Allavena P, Erba E, D'Incalci M: Comparison of in vitro and in vivo biological effects of trabectedin, lurbinectedin (PM01183) and Zalypsis ${ }^{\circledast}$ (PM00104). Int J Cancer 2013, 133(9):2024-2033.

27. Smyth GK: Linear models and empirical bayes methods for assessing differential expression in microarray experiments. Stat Appl Genet Mol Biol 2004, 3:Article3.

28. Pignochino Y, Sarotto I, Peraldo-Neia C, Penachioni JY, Cavalloni G, Migliardi G, Casorzo L, Chiorino G, Risio M, Bardelli A, Aglietta M, Leone F: Targeting EGFR/HER2 pathways enhances the antiproliferative effect of gemcitabine in biliary tract and gallbladder carcinomas. BMC Cancer 2010, 10:631.

29. Mosnier JF, Kandel C, Cazals-Hatem D, Bou-Hanna C, Gournay J, Jarry A, Laboisse CL: N-cadherin serves as diagnostic biomarker in intrahepatic and perihilar cholangiocarcinomas. Mod Pathol 2009, 22(2):182-190.

30. Rivat C, Christine R, Rodrigues S, Sylvie R, Bruyneel E, Erik B, Piétu G, Geneviève $P$, Robert A, Amélie R, Rivat $C$, Rodrigues S, Bruyneel E, Piétu G, Robert A, Redeuilh G, Bracke M, Gespach C, Attoub S: Implication of STAT3 signaling in human colonic cancer cells during intestinal trefoil factor 3 (TFF3) - and vascular endothelial growth factor-mediated cellular invasion and tumor growth. Cancer Res 2005, 65(1):195-202.

31. Shimizu T, Yokomuro S, Mizuguchi $Y$, Kawahigashi $Y$, Arima $Y$, Taniai $N$, Mamada Y, Yoshida H, Akimaru K, Tajiri T: Effect of transforming growth factor-beta1 on human intrahepatic cholangiocarcinoma cell growth. World J Gastroenterol 2006, 12(39):6316-6324.

32. Benckert $C$, Jonas $S$, Cramer T, Von Marschall Z, Schäfer $G$, Peters M, Wagner $K$, Radke C, Wiedenmann B, Neuhaus P, Höcker M, Rosewicz S: Transforming growth factor beta 1 stimulates vascular endothelial growth factor gene transcription in human cholangiocellular carcinoma cells. Cancer Res 2003, 63(5):1083-1092

33. André T, Tournigand C, Rosmorduc O, Provent S, Maindrault-Goebel F, Avenin D, Selle F, Paye F, Hannoun L, Houry S, Gayet B, Lotz JP, de Gramont A, Louvet $C$ : Gemcitabine combined with oxaliplatin (GEMOX) in advanced biliary tract adenocarcinoma: a GERCOR study. Ann Oncol 2004, 15(9):1339-1343.

34. Gütgemann I, Haas S, Berg JP, Zhou H, Büttner R, Fischer HP: CD56 expression aids in the differential diagnosis of cholangiocarcinomas and benign cholangiocellular lesions. Virchows Arch 2006, 448(4):407-411.

35. Isomoto H: Epigenetic alterations in cholangiocarcinoma-sustained IL-6/STAT3 signaling in cholangio- carcinoma due to SOCS3 epigenetic silencing. Digestion 2009, 79(Suppl 1):2-8.

36. El Khatib M, Kalnytska A, Palagani V, Kossatz U, Manns MP, Malek NP, Wilkens L, Plentz RR: Inhibition of hedgehog signaling attenuates carcinogenesis in vitro and increases necrosis of cholangiocellular carcinoma. Hepatology 2013, 57(3):1035-1045.

37. Riedlinger D, Bahra M, Boas-Knoop S, Lippert S, Bradtmöller M, Guse K, Seehofer D, Bova R, Sauer IM, Neuhaus P, Koch A, Kamphues C: Hedgehog pathway as a potential treatment target in human cholangiocarcinoma. $J$ Hepatobiliary Pancreat Sci 2014, 21(8):607-615.

38. Zhang KS, Zhou Q, Wang YF, Liang LJ: Inhibition of Wnt signaling induces cell apoptosis and suppresses cell proliferation in cholangiocarcinoma cells. Oncol Rep 2013, 30(3):1430-1438.

39. Redon C, Pilch D, Rogakou E, Sedelnikova O, Newrock K, Bonner W: Histone H2A variants H2AX and H2AZ. Curr Opin Genet Dev 2002, 12(2):162-169.

40. Guirouilh-Barbat J, Redon C, Pommier Y: Transcription-coupled DNA double-strand breaks are mediated via the nucleotide excision repair and the Mre11-Rad50-Nbs1 complex. Mol Biol Cell 2008, 19(9):3969-3981.
41. Bertotti A, Migliardi G, Galimi F, Sassi F, Torti D, Isella C, Corà D, Di Nicolantonio F, Buscarino M, Petti C, Ribero D, Russolillo N, Muratore A, Massucco P, Pisacane A, Molinaro L, Valtorta E, Sartore-Bianchi A, Risio M, Capussotti L, Gambacorta M, Siena S, Medico E, Sapino A, Marsoni S, Comoglio PM, Bardelli A, Trusolino L: A molecularly annotated platform of patient-derived xenografts ("xenopatients") identifies HER2 as an effective therapeutic target in cetuximab-resistant colorectal cancer. Canc Discov 2011, 1(6):508-523.

42. Bertotti A, Trusolino L: From bench to bedside: does preclinical practice in translational oncology need some rebuilding? J Natl Cancer Inst 2013, 105(19):1426-1427.

43. Tanaka S, Sugimachi K, Kameyama T, Maehara S, Shirabe K, Shimada M, Wands JR, Maehara Y: Human WISP1v, a member of the CCN family, is associated with invasive cholangiocarcinoma. Hepatology 2003, 37(5):1122-1129.

44. Ailawadhi S, Nagase H, Khoury T, Yu J, Tan D, Black J, Brattain M, Javle M: Intestinal trefoil factor (TFF-3) and extracellular signal-regulated kinase (ERK) in cholangiocarcinoma. Hepatogastroenterology 2007, 54(77):1339-1344.

doi:10.1186/1471-2407-14-918

Cite this article as: Peraldo-Neia et al:: Anti-cancer effect and gene modulation of ET-743 in human biliary tract carcinoma preclinical models. BMC Cancer 2014 14:918.

\section{Submit your next manuscript to BioMed Central and take full advantage of:}

- Convenient online submission

- Thorough peer review

- No space constraints or color figure charges

- Immediate publication on acceptance

- Inclusion in PubMed, CAS, Scopus and Google Scholar

- Research which is freely available for redistribution 